\title{
Impuestos verdes
}

\section{Desafíos para}

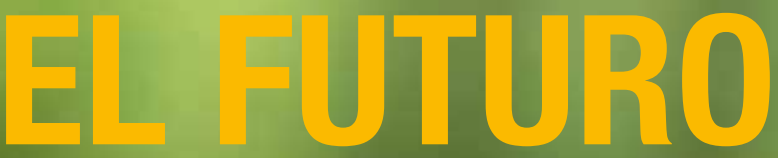

Chile es el primer país de la región en implementar este tipo de

tributación. Sin embargo, todavía quedan desafíos legales que

definir y que deberán abordarse con prontitud.

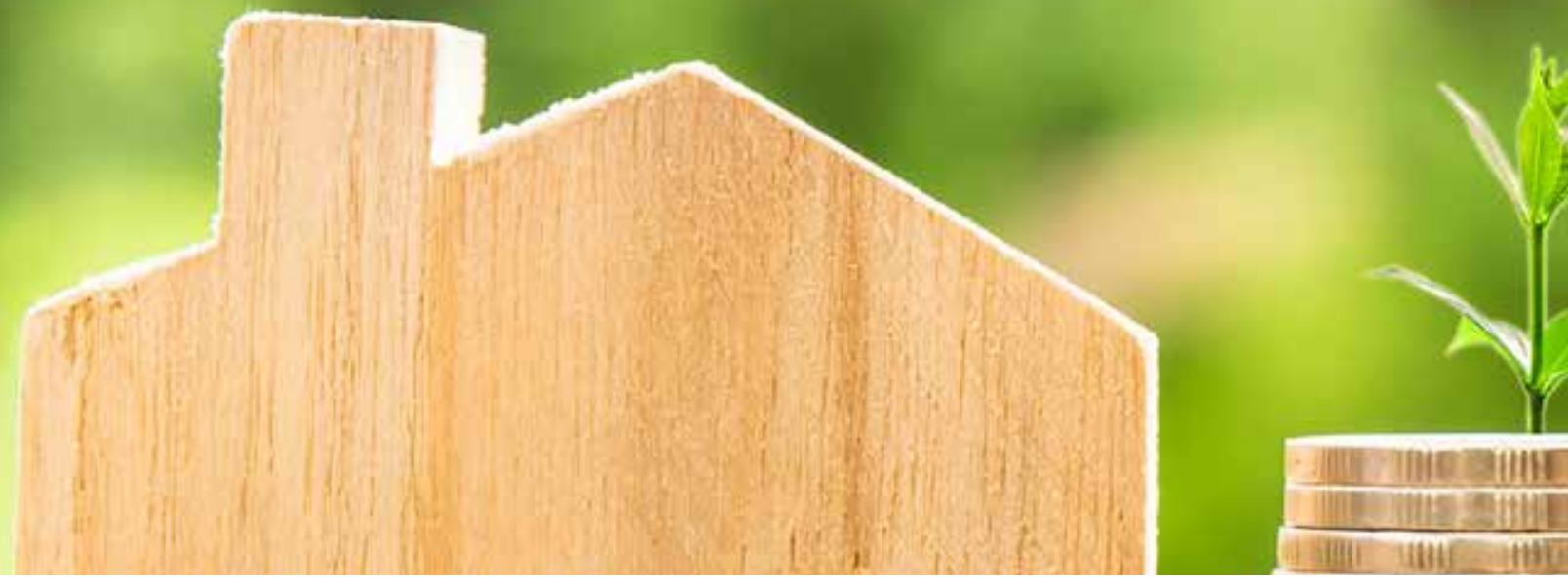

Por: Evangelina Dardati, Ph.D. en Economía, University of Texas at Austin, EE.UU., académica FEN-UAH

a ley 20.780 de 2014 implementó los impuestos verdes gravando las emisiones de material particulado (MP), óxido de nitrógeno (NOx), dióxido de azufre (SO2) y dióxido de carbono (CO2). Mientras los tres primeros son contaminantes locales que afectan la salud de las personas, el $\mathrm{CO} 2$ es un contaminante global, principal causa del cambio climático. Los establecimientos afectados por la ley son sólo aquellos con fuentes fijas conformadas por calderas o turbinas cuya potencia térmica sea mayor a $50 \mathrm{MWt}$ (megavatios térmicos).

Desde un punto de vista económico, un impuesto eficiente debe ser igual al daño marginal de la contaminación. Así, las fuentes contaminarán hasta que su costo marginal de reducir la contaminación se iguale al impuesto.

Si a una empresa le cuesta más caro reducir la contaminación que pagar el impuesto preferirán pagar. Si por el contrario, les resulta más alto el impuesto que bajar la contaminación preferirán hacer esto último. Así se cumple lo que se conoce como principio de equimarginalidad, donde los costos marginales de disminuir la contaminación se igualan entre las diferentes fuentes contaminantes. Cuando esto se cumple, la contaminación se reduce al menor costo posible. Los impuestos tienen esta ventaja a diferencia de otros tipos de regulación ambiental como los instrumentos de comando y control. En este sentido, la implementación de estos impues- tos en Chile es un gran avance.

Ahora bien, ¿como elegir el impuesto óptimo? En el caso de los contaminantes locales, conocer el daño no es fácil ya que depende de muchos factores. Algunos tienen que ver con la capacidad de difusión entre zonas, y con la magnitud de la población afectada por estas emisiones. En este sentido, el impuesto establecido en Chile contempla alguno de estos factores. Por un lado, se paga considerando la población de la comuna afectada (a más población mayores daños y mayor impuestol donde se contamina y dependiendo de cuán afectada esté el área (zona "saturada" o "latente). Lo que el impuesto no considera es el efecto propagación hacia otras áreas. Sin embargo, la fórmula se acerca bastante a un impuesto óptimo.

En cuanto a las emisiones de $\mathrm{CO} 2$, la ley establece un impuesto de 5 dólares por tonelada de carbón. En este caso, el gravamen es demasiado bajo comparando con lo que lo que se estableció como costo social del carbón en otros países, donde en general va de 20 a 70 dólares por tonelada.

La ley comenzó a implementarse en 2017. Los ingresos fiscales por el impuesto a las fuentes fijas fueron el primer año de 191,4 millones de dólares. De esta recaudación, un $88 \%$ corresponde al impuesto al C02. Después de esta primer experiencia quedaron en evidencia algunos problemas en la ley. Algunos aspectos están siendo discutidos para ser modificados en el corto plazo. 


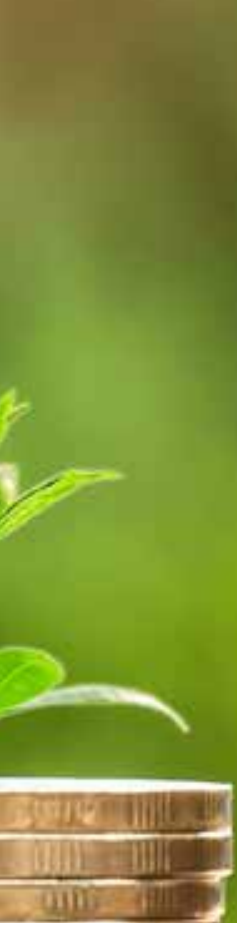

Una de las primeras modificaciones que se están evaluando es gravar a fuentes con emisiones de clara importancia. En vez de hacerlo a establecimientos que tengan un mínimo de capacidad, se gravaría a aquellas emisoras que contaminen más de 100 toneladas anuales de material particulado 0 más de 25 mil toneladas anuales de $\mathrm{CO} 2$. Esto incrementaría las fuentes fijas afectadas por el impuesto. También se establecería la posibilidad de compensar las emisiones de $\mathrm{CO} 2$ si se implementan proyectos de reducción de emisiones.

Otro tema importante de la ley es que el impuesto no se tiene en cuenta para el despacho del sistema eléctrico. Esto implica que las tecnologías más contaminantes generalmente sean despachadas antes que las fuentes renovables siendo estas primeras compensadas por el sistema. Esta compen-

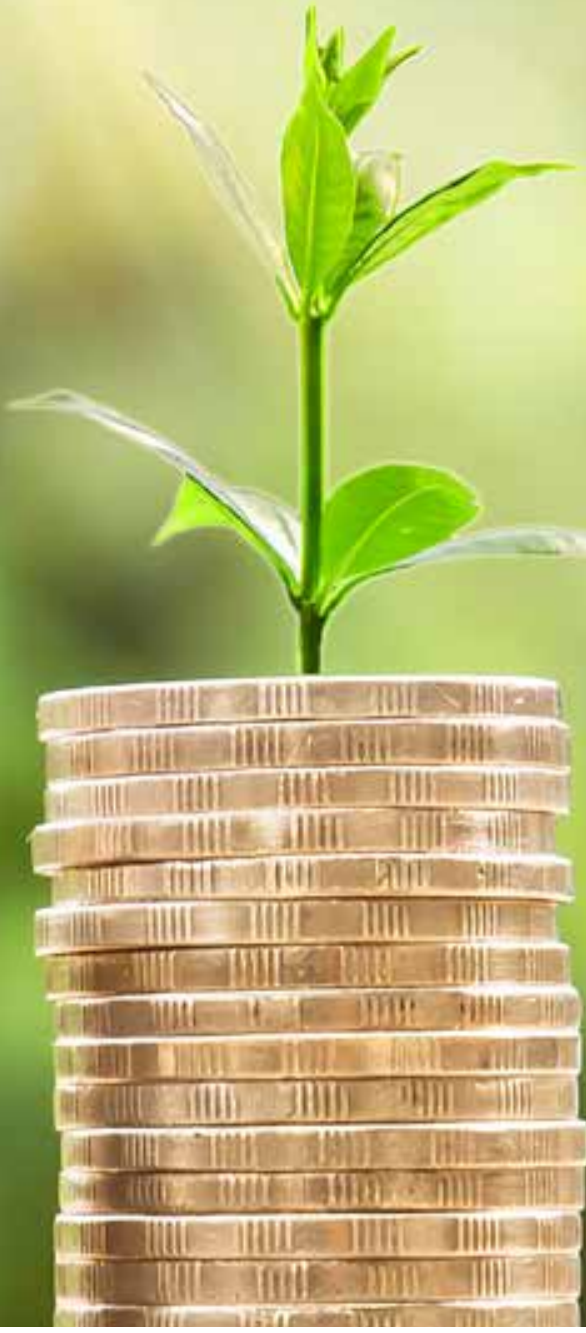

sación puede ser una proporción importante del impuesto que deben pagar, dando una señal errónea al sistema tendiendo en algunos casos a en parte neutralizar el efecto medioambiental del impuesto. Sin embargo, hay que recordar que el sector eléctrico ya tiene una regulación anterior al impuesto cuya finalidad es incentivar el uso de fuentes renovables. El mercado de certificados verdes establece que toda empresa que retire energía del sistema deberá acreditar inyecciones de Energía Renovable No Convencional (ERNC) equivalente a un $7 \%$ de dicho retiro (este monto subirá a $10,4 \%$ para 2024).

No es claro como estas dos regulaciones interactúan entre sí y si, quizás, sería mejor tener una sola. Esto requiere un cuidadoso análisis para establecer la regulación óptima y asegurarnos que los merca- dos estén generando las señales de precios correctas.

Un tema que tendrá que considerarse a mediano plazo, que no es menor, es el del monto del impuesto al C02. Un impuesto muy bajo no permitiría que Chile cumpliera con los acuerdos internacionales de reducción del contaminante. Sin embargo, un aumento del mismo generaría grandes costos al sistema con impactos para todo el país. Cómo integrar esa decisión con la evolución del parque generador eléctrico y su mix es el desafío pendiente.

En definitiva, Chile es el primer país de la región en implementar este tipo de tributación lo cual es un avance importante. Sin embargo, todavía quedan desafíos legales que definir y que deberán abordarse con prontitud porque no sólo tienen implicancias ambientales sino también sobre la inversión futura. $\mathbf{E}$ 